\title{
Zooplanktivory is a key process for fish production on a coastal artificial reef
}

\author{
Curtis Champion ${ }^{1, *}$, Iain M. Suthers ${ }^{1}$, James A. Smith ${ }^{1}$ \\ ${ }^{1}$ Evolution and Ecology Research Centre, School of Biological, Earth and Environmental Sciences, \\ University of New South Wales, Sydney, NSW 2052, Australia
}

ABSTRACT: Artificial reefs continue to be deployed in coastal areas to enhance local fisheries. An important factor influencing the success of artificial reefs may be the provision of refuge for zooplanktivorous fishes, which use artificial reefs as a base to forage the surrounding zooplankton. A numerical model was developed to quantify this trophic pathway on a designed coastal artificial reef, using field-parameterised data for zooplankton biomass, current velocity, and the consumption rate and abundance of a reef-resident zooplanktivorous fish (Atypichthys strigatus). The model estimated that this species consumed $\sim 2.9 \mathrm{~kg}\left(1.0 \mathrm{~g} \mathrm{~m}^{-3}\right)$ of zooplankton per day on this artificial reef, which represents only $0.35 \%$ of the total zooplankton biomass. The ability of this artificial reef to support $\sim 130 \mathrm{~kg}$ standing stock of this species suggests that the zooplankton pathway is a reliable mechanism for fish production. A second model explored the influence of reef size on zooplanktivorous fish densities and the supply of zooplankton required to sustain their consumption rate. As reef size increased, the ratio between the foraging volume and refuge volume declined, meaning that small reefs have lots of food and not much refuge, and large reefs can have lots of refuge but not enough food. This indicates that reef size can be manipulated to maximise fish abundance while avoiding food limitation. Reef size, shape, and orientation should be considered carefully during the planning of artificial reefs, as it can greatly influence the foraging of reef-resident zooplanktivorous fishes and thus influence the entire reef assemblage.

KEY WORDS: Artificial reefs - Zooplankton · Zooplanktivorous fish · Foraging halo - Atypichthys strigatus · Trophic ecology

\footnotetext{
*Corresponding author: curtischampo@hotmail.com
}

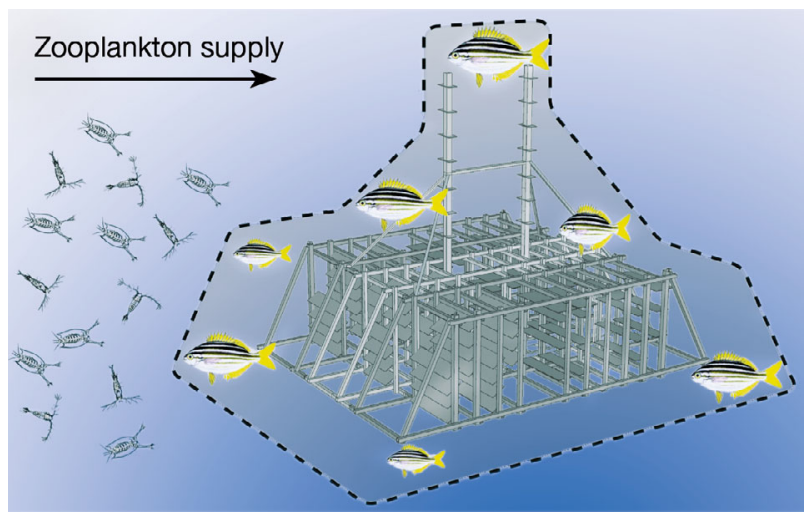

Artificial reefs provide zooplanktivorous fishes with habitat (bounded by the dashed line), allowing them to safely access the zooplankton supply that drives their production.

Diagram: C. Champion

\section{INTRODUCTION}

Artificial reefs are often deployed in coastal marine areas to create fishing opportunities, promote biodiversity, and restore degraded habitats (Miller 2002, Claudet \& Pelletier 2004, Seaman 2007). This is especially true of designed artificial reefs, which, unlike materials of opportunity (Seaman et al. 1989), are built and deployed to achieve specific environmental objectives (Pickering \& Whitmarsh 1997, Baine 2001). Artificial reefs are popular fisheries enhancement tools because fish biomass often increases in surrounding waters after their deployment (Bombace et al. 1994, Charbonnel et al. 2002, Leitão 2013). Whether increases in fish biomass involve new production or simply attraction of existing biomass is debated (Bohnsack 1989, Grossman et al. 1997, Pow-

() The authors 2015. Open Access under Creative Commons by Attribution Licence. Use, distribution and reproduction are unrestricted. Authors and original publication must be credited. 
ers et al. 2003, Brickhill et al. 2005). It is generally agreed, however, that artificial reefs can provide habitat space and food resources for fishes (Peterson et al. 2003, Powers et al. 2003, Cresson et al. 2014), and it is this provision of refuge and food that is most likely to drive any production of fish biomass on these reefs (Charbonnel et al. 2002, Powers et al. 2003). Thus, quantitative research is needed to explore how artificial reefs influence fish production via these factors.

The capacity for artificial reefs to increase habitat space and the availability of food is exemplified by the trophic link between zooplankton and reefresident zooplanktivorous fishes. Zooplanktivores can be a dominant feeding guild in a variety of ecological contexts (Hobson \& Chess 1976, 1978, Ebeling et al. 1980, Edgar et al. 2014) and can be extremely abundant on coastal artificial reefs (Scott et al. 2015). Their capacity to continuously access zooplankton supplied by prevailing coastal currents indicates that increasing the provision of reef habitat may allow for increased production of zooplanktivorous fishes. Zooplanktivores are readily preyed upon by piscivorous species (Young et al. 2010) and thus require the refuge provided by artificial reefs to forage the surrounding zooplankton. This suggests that the productivity of artificial reefs, and their subsequent contribution to local fisheries, may be largely dependent on the direct and underappreciated trophic link between zooplankton and reef-resident zooplanktivorous fishes.

There is evidence to suggest that a balance of predation risk and foraging success influences the association of fish with reefs (Frazer \& Lindberg 1994, Biesinger et al. 2011, 2013), specifically the maximum distance from refuge habitat that prey fish will forage (Biesinger et al. 2011). The distance that reefresident zooplanktivorous fish will forage from refuge determines the total volume of water surrounding a reef that is available to be foraged, and it is likely that this distance is largely independent of reef size (Scott et al. 2015). Thus, reef size (i.e. refuge habitat size) would not scale linearly with the surrounding foraging volume, which has interesting implications for food availability and reef-resident zooplanktivore density. The clear spatial boundaries of artificial reefs make them ideal sites to investigate this influence of reef size on the dynamics of reef-resident zooplanktivorous fishes.

The goal of this study was to explore the contribution of zooplanktivory to the production of fish biomass on artificial reefs and the management implications of this ecological process. Specifically, this study aimed to (1) describe the diet and habitat use of an abundant zooplanktivorous fish on a designed coastal artificial reef, (2) estimate the depletion of zooplankton due to predation by zooplanktivorous fish on this reef, and (3) illustrate the influence of artificial reef size on foraging volume and food availability for resident zooplanktivores.

\section{MATERIALS AND METHODS}

\section{Location}

This study was conducted at a coastal artificial reef that was deployed in October 2011, located $1.2 \mathrm{~km}$ off the coast of Sydney, NSW, Australia (33 50.797' S, $151^{\circ} 17.988^{\prime} E_{i}$ Fig. 1). The reef was designed to increase fishing opportunities for recreational anglers, is 15 by $12 \mathrm{~m}$ and $12 \mathrm{~m}$ tall, including $8 \mathrm{~m}$ high spires (Fig. 2). It is made of steel, and is located at a bottom depth of $38 \mathrm{~m}$ (Scott et al. 2015). The nearest natural reef of any significance is located $\sim 600 \mathrm{~m}$ inshore from the artificial reef. Nine sampling trips to collect fish and zooplankton data were made from February to August 2014.

\section{Dietary analysis of Atypichthys strigatus}

The fish species chosen for this study was mado $A$. strigatus (Günther). They are small reef-resident zooplanktivores common to the temperate reefs of southeastern Australia (Glasby \& Kingsford 1994, Fowler \& Booth 2013) and are one of the most abundant fishes found on this study's artificial reef (NSW Department of Primary Industries 2013, Scott et al. 2015). Fiftyfive A. strigatus were sampled from the reef using hook-and-line fishing, frozen on collection, and later

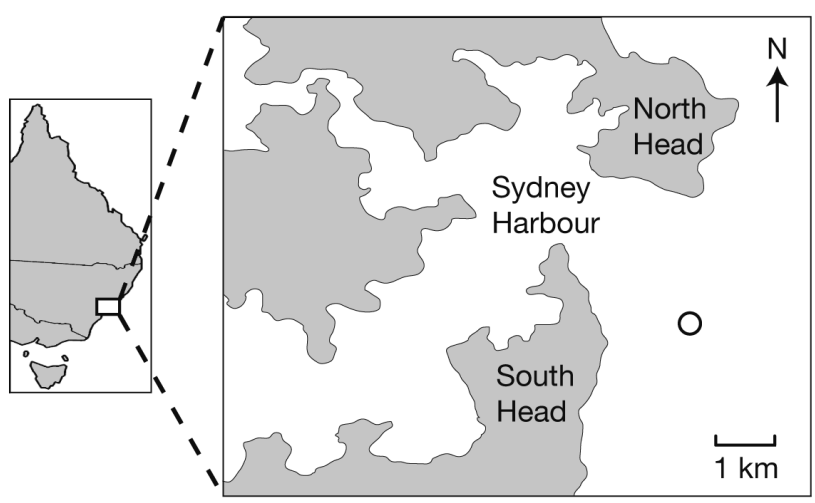

Fig 1. Location in Australia of the coastal artificial reef used in this study (circle) 


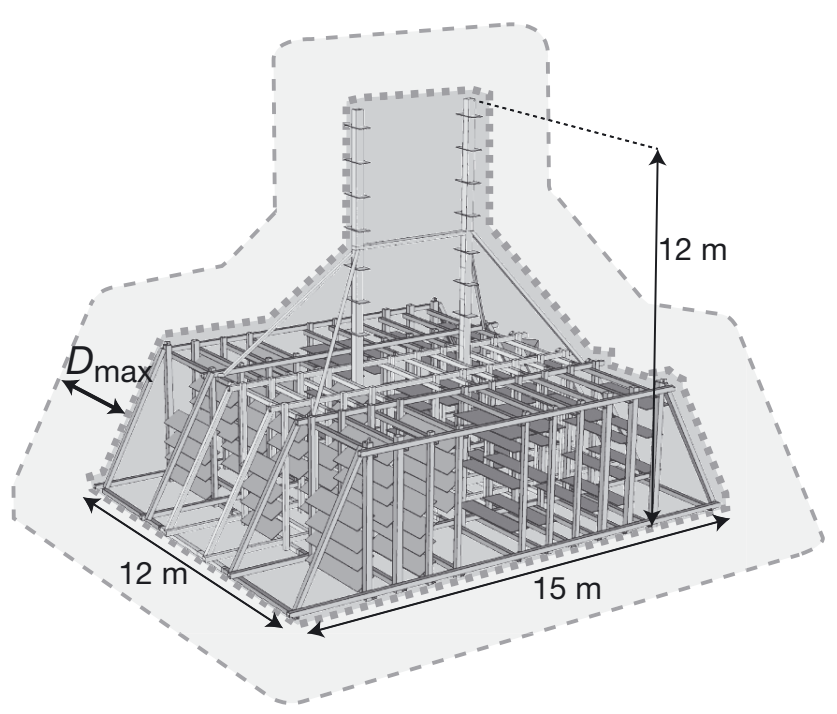

Fig. 2. Illustration of the reef volume (dark grey) and the foraging volume (light grey) surrounding this study's artificial reef $(12 \times 15 \times 12 \mathrm{~m}) . D_{\max }$ is the maximum distance that Atypichthys strigatus generally forage from the reef, and it determines the total volume of water available to be foraged

dissected with their stomachs stored in $5 \%$ formaldehyde. The diet of $A$. strigatus was determined by gravimetric analyses of stomach contents (Hyslop 1980). Total prey biomass and diet composition by mass were quantified for each individual. Stomach contents were sorted into broad taxonomic groups, and groups were dried separately at $60^{\circ} \mathrm{C}$ (Man \& Hodgkiss 1977) to determine their respective dry weights (Berg 1979). The dry weight ratio of prey groups to total stomach contents was used to determine the corresponding wet biomass of individual prey groups, as wet and dry weights are highly correlated (Glenn \& Ward 1968). Wet weight values were subsequently used to calculate the proportion of the A. strigatus diet comprised of zooplankton.

\section{Density and foraging volume of $\boldsymbol{A}$. strigatus}

It was necessary to estimate the density of $A$. strigatus at the reef in order to estimate the total consumption of zooplankton, and this was conducted using underwater video surveys. Video surveys were done using cameras lowered to the reef from a boat ('drop cameras') during periods when the reef was not being fished. Five replicate drop cameras, each of 10 min duration, were done on separate days to sample the abundance of $A$. strigatus. Drop cameras could not survey inside the reef, so the density of A. strigatus within the reef was estimated using a remotely operated vehicle (ROV; Seamor Marine). Two ROV surveys of the reef were done, each for $\sim 30 \mathrm{~min}$ in duration. The average abundance of $A$. strigatus was estimated from 80 still frames, randomly selected from all suitable drop camera and ROV footage. Abundance was converted to density by estimating the volume of water in each still frame, using camera field-of-view and the day-specific viewing distance (i.e. water visibility). The drop camera field-of-view (in both vertical and horizontal planes) was calculated in an ocean swimming pool by filming a known area of a vertical surface from a known distance, while the ROV field-of-view was estimated using the ROV's laser scaler. Viewing distance was calculated on each day by lowering a camera fixed above an array of black and white rods at known distances from the camera (J. A. Smith, W. K. Cornwell, M. B. Lowry, I. M. Suthers unpubl.). To refine the spatial distribution of $A$. strigatus around the reef, fish density was partitioned into $0.5 \mathrm{~m}$ distance bins (e.g. 0.5-1 $\mathrm{m}$ from the reef). This was done by estimating the distance of individual $A$. strigatus from the reef, achieved by relating their locations in each still frame to known distances between the reef's structural features (e.g. vertical and horizontal beams). Likewise, the total volume of water in each snapshot was partitioned into distance bins to estimate bin-specific fish densities.

The reef volume and the surrounding foraging volume had to be determined to calculate total $A$. strigatus abundance from the above density estimates. Engineering diagrams were used to calculate the volume of water within the reef (hereafter 'reef volume'), and the surrounding volume as distance from the reef increased (hereafter 'foraging volume'; Fig. 2). Total reef volume and the volume of water held within $0.5 \mathrm{~m}$ foraging bins extending from the structure were combined with bin-specific density estimates to calculate $A$. strigatus abundance within each bin.

\section{Consumption by $A$. strigatus}

Food consumption as a function of biomass $\left(Q / B \mathrm{yr}^{-1}\right)$ was estimated using an empirical formula derived by Palomares \& Pauly (1998), which is a common method to predict consumption rates of marine fishes (e.g. Hughes et al. 2014),

$\log _{10} \frac{Q}{B}=$ 
where $W_{\infty}$ is the asymptotic weight of an individual (g), $T^{\prime}$ is the mean water temperature (equal to $\left.1000 / T^{\circ} \mathrm{C}+273.1\right), A R$ is the aspect ratio of the caudal fin, and $h$ and $d$ are dummy variables relating to feeding preference; i.e. carnivore $(m=0, d=0)$, detritivore $(m=0, d=1)$, or herbivore $(m=1, d=0)$. Both $m$ and $d$ were set to 0 due to $A$. strigatus being predominantly zooplanktivorous (Glasby \& Kingsford 1994). Caudal fin aspect ratio is a species-specific morphometric variable described by:

$$
A R=\frac{h^{2}}{S}
$$

where $h$ and $s$ refer to the height $(\mathrm{cm})$ and lateral surface area of the caudal fin (to the caudal peduncle; $\mathrm{cm}^{2}$ ), respectively. $A R$ is a proxy of the metabolic functioning of fishes and generally increases as fish activity increases (Palomares \& Pauly 1989). An average $A R$ was calculated from 53 A. strigatus across a broad size range. $W_{\infty}$ was calculated by converting asymptotic length $\left(L_{\infty} ; \mathrm{cm}\right)$ to weight $(\mathrm{g})$ using a standard length-weight relationship $(a=0.03 ; b=2.90)$. $L_{\infty}$ was taken to be $25 \mathrm{~cm}$ (total length, TL) as reported by the Australian Museum. Water temperature was measured on each sampling day using a SBE 19-plus V2 SeaCAT Profiler CTD (Sea-Bird Electronics Inc.) at depths relevant to the reef (24-38 m).

\section{Zooplankton supply and availability}

The supply of zooplankton was measured using plankton tows between 50 and $200 \mathrm{~m}$ up-current from the artificial reef. This was done up-current to ensure sampled zooplankton had not been exposed to consumption by this reef's residents. Given the depth and comparatively small size of this reef, it was impractical to attempt a corresponding downstream sample of zooplankton as in Hamner et al. (1988), so the depletion of zooplankton could only be modelled. A $40 \mathrm{~cm}$ diameter, $100 \mu \mathrm{m}$ mesh plankton net was towed horizontally from a boat for $4 \mathrm{~min}$ per tow, 15-20 $\mathrm{m}$ from the surface. The distance of each tow was calculated using a GPS, and each tow sampled $\sim 25 \mathrm{~m}^{3}$ of seawater. Three replicate tows were done per sampling day (n = 27). Plankton samples were preserved with $5 \%$ formaldehyde immediately after collection. Samples were inspected under a dissecting microscope to ensure they contained only zooplankton and were then sorted using a laser optical plankton counter (LOPC; Herman et al. 2004). The LOPC sorts particles into size classes and estimates total count and biomass $\left(\mathrm{mg} \mathrm{m}^{-3}\right.$ ) per size class (Suthers et al. 2004).
It is known that the visual acuity of zooplanktivorous fishes affects patterns of prey size-selection by limiting their detection of small items (O'Brien 1979, Wankowski 1979, Li et al. 1985). Thus, an analysis of prey sizes in stomach contents of A. strigatus was done to quantify their pattern of prey size-selection. The stomach contents of 55 A. strigatus were examined for zooplankton, and between 30 and 50 zooplankton prey items per fish were randomly sampled and measured using a microscope. Zooplankton were placed in $200 \mu \mathrm{m}$ size class bins based on their equivalent spherical diameter (ESD). The proportions of zooplankton size classes found in fish stomachs were compared to the proportions found in the plankton tows to refine the biomass of zooplankton that is available for consumption by $A$. strigatus $\left(B a_{i}\right.$ see Eq. S2 in the Supplement text; www.int-res.com/ articles/supp/m540p001_supp.pdf). This available biomass was used in calculations estimating the percentage depletion of zooplankton by $A$. strigatus.

Mean current velocities were used to estimate the supply of zooplankton per unit time to the foraging volume of $A$. strigatus. Current velocities were attained using a mechanical flow meter attached to the reef, which measured average velocity at 10 min intervals from June-August 2013 and from December 2013February 2014.

\section{Model 1: Zooplankton depletion}

A mathematical model was developed to estimate the depletion of zooplankton caused by A. strigatus predation at the coastal artificial reef in this study. This model predicted the depletion of each size class of zooplankton by incorporating zooplankton biomass, current velocity, and the consumption rate, density, and foraging volumes of A. strigatus. A Monte Carlo simulation was used to include parameter variation in the model, and this is detailed in 'Monte Carlo simulation and sensitivity analysis'. See Table 1 for parameter descriptions and values.

Zooplankton depletion by A. strigatus at this artificial reef was calculated as:

$$
\operatorname{Dep}_{i}=\frac{C_{i}}{B b_{i}}
$$

where $D e p_{i}$ is the proportional depletion of zooplankton biomass from size class $i(i=9)$, and $B b_{i}$ $\left(\mathrm{mg} \mathrm{m}^{-3}\right)$ is the total biomass of zooplankton within size class $i$ before predation by $A$. strigatus. $B b_{i}$ was also replaced by $B a_{i}$ (Eq. S2 in the Supplement) to calculate the depletion of only the zooplankton bio- 
Table 1. All model parameters (Sens.: ${ }^{*}=$ parameters included in a sensitivity model), their mean values, and the distributions and associated variance used in the Monte Carlo analysis. Normal $(N)$, lognormal (ln $N$ ), and beta sampling distributions (Beta) were used, and numbers within brackets represent each distribution's sampling parameters, as defined using $\mathrm{R}$ (R Core Team 2015) notation. na: parameters for which uncertainty was not necessary or not logical. Figs. S2 \& S3 and Eq. (S1) are in the Supplement

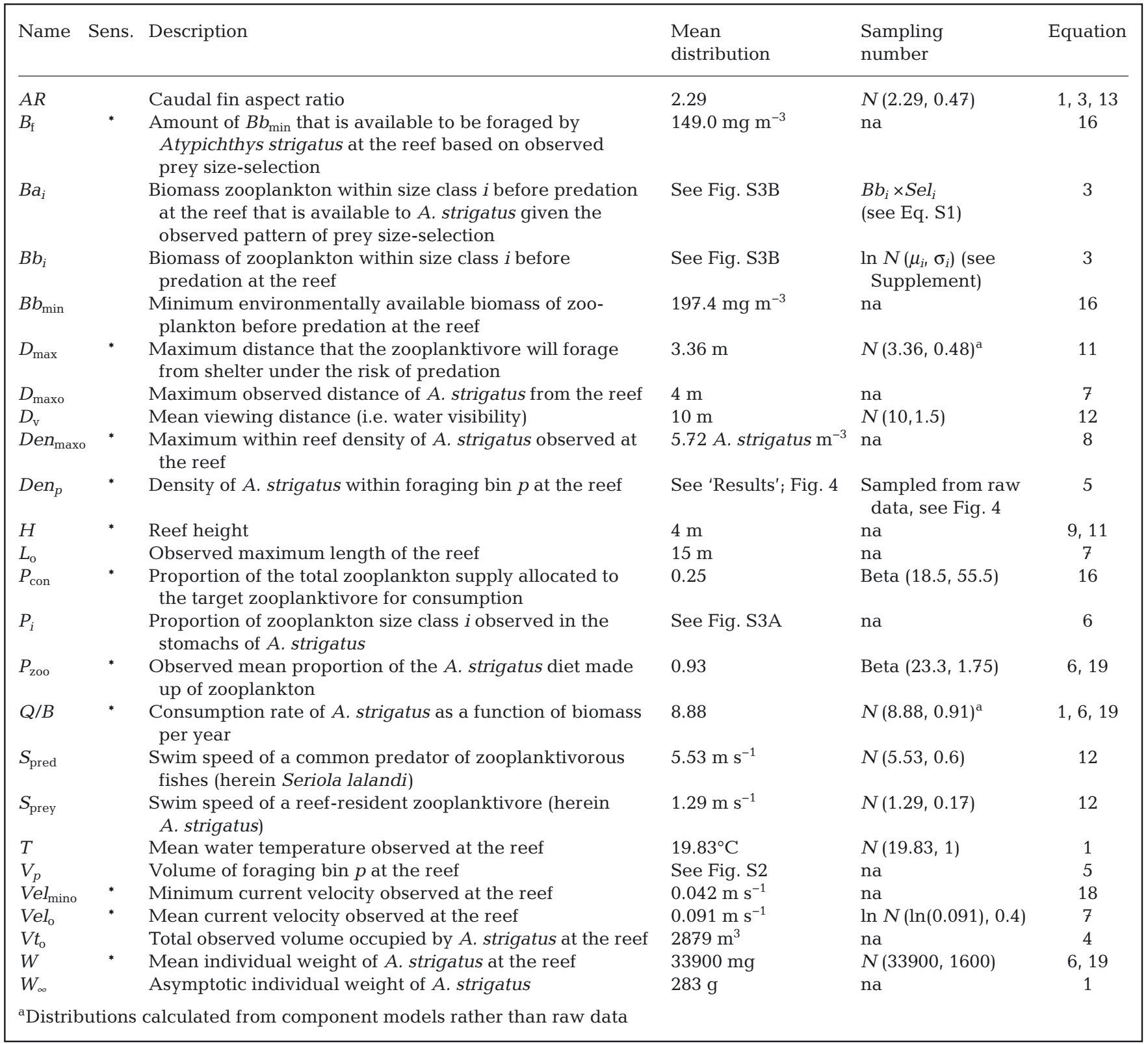

mass that is within the size range available to $A$. strigatus predation. $C_{i}$ is the consumption of zooplankton size class $i$ by A. strigatus in the duration that the zooplankton supply is exposed to predation. This duration was determined by current velocity and is termed a 'period' (Eq. 7). Thus, $C_{i}$ has the unit $\mathrm{mg} \mathrm{m}^{-3}$ period $^{-1}$ and is the sum of the consumption in the nine $0.5 \mathrm{~m}$-wide foraging volume bins $(p)$, calculated as:

$$
C_{i}=\frac{\sum_{p=1}^{9}\left(\operatorname{Cin}_{i} \times N_{p}\right)}{V t_{\mathrm{o}}}
$$

where $V t_{\mathrm{o}}$ was the total volume $\left(\mathrm{m}^{3}\right)$ occupied by $A$. strigatus at the reef (within-reef volume plus surrounding foraging volume), calculated using the maximum observed distance of $A$. strigatus from the reef $\left(D_{\text {maxo }}\right)$ during video surveys. $\mathrm{Cin}_{i}$ (mg A. strigatus $^{-1}$ period $^{-1}$ ) is the consumption of zooplankton size 
class $i$ by an individual $A$. strigatus per period, and $N_{p}$ is the total abundance of $A$. strigatus within foraging volume bin $p$, calculated as:

$$
N_{p}=\operatorname{Den}_{p} \times V_{p}
$$

where $\operatorname{Den}_{p}$ is the density of $A$. strigatus within foraging bin $p$ (A. strigatus $\mathrm{m}^{-3}$ ), and $V_{p}$ is the volume of foraging bin $p\left(\mathrm{~m}^{3}\right)$.

$\mathrm{Cin}_{i}$ was calculated:

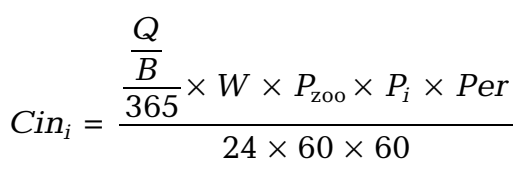

where $W(\mathrm{mg})$ is the mean individual weight of $A$. strigatus at the reef $(\mathrm{n}=55), P_{\mathrm{zoo}}$ is the observed mean proportion of the $A$. strigatus diet made up of zooplankton, $P_{i}$ is the proportion of zooplankton size class $i$ observed in the stomachs of A. strigatus ( $\mathrm{n}=$ 55), and Per is the mean time (s) taken for water to move completely through the foraging volume of $A$. strigatus (a 'period'), calculated as:

$$
\text { Per }=\frac{\left(L_{\mathrm{o}}+2 \times D_{\operatorname{maxo}}\right)}{V e l_{\mathrm{o}}}
$$

where $L_{\mathrm{o}}$ is the observed maximum length of the reef (m); $D_{\text {maxo }}$ is the maximum distance that $A$. strigatus were observed from the reef $(\mathrm{m})$; and $\mathrm{Vel}_{\mathrm{o}}$ is the mean current velocity observed at the reef $\left(\mathrm{m} \mathrm{s}^{-1}\right)$.

\section{Model 2: Reef size}

A general model was developed to identify how the size of an artificial reef influences the availability of food relative to the availability of habitat for reefresident zooplanktivorous fish such as A. strigatus (Fig. 3). Specifically, this model was used to identify how artificial reef size influences the ratio of the total zooplankton supply (food supplied) to the required consumption of a reef's maximum zooplanktivore population (food required). This model focused on the relationship between reef size and foraging volume, which is non-linear because the maximum foraging distance $\left(D_{\max }\right)$ for reef residents using the reef as a refuge is a constant that is generally independent of reef size (Biesinger et al. 2011). This is demonstrated in Fig. 3, in which per-capita food availability is highest when reef volume is small and foraging volume relative to reef volume (the $V f: V r$ ratio) is large (Fig. 3A). Refuge is most abundant when reef volume is large, but foraging volume relative to reef volume is small and food limitation will, at some point, limit the density of fish (Fig. 3B). Model 2 was
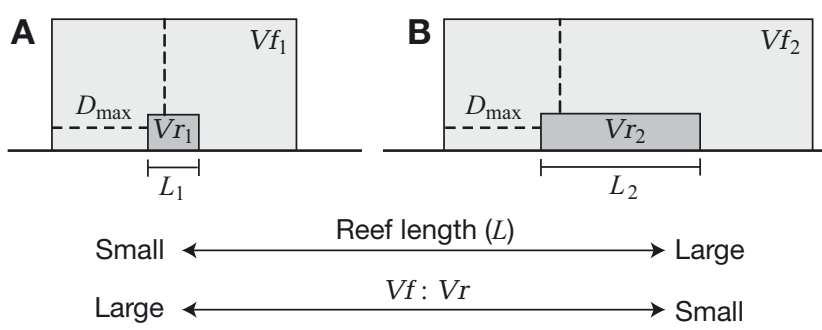

Fig. 3. Conceptual schematic of the changing relationship between food availability and refuge availability with a changing reef size. Food availability depends on the foraging

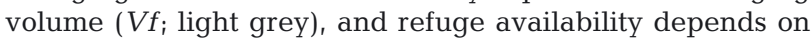
the reef volume ( $V r_{i}$ dark grey); and the ratio between these $(V f: V r)$ declines as reef size increases. A hypothetical example is 2 square reefs of height $1 \mathrm{~m}$, with $L_{1}=1 \mathrm{~m}$ and $L_{2}=3 \mathrm{~m}$, and $D_{\max }=4 \mathrm{~m}$. This gives $V f_{1}: V r_{1}=404$ for the smaller reef, which declines to $V f_{2}: V r_{2}=66.2$ for the larger reef

also designed to explore management implications associated with artificial reef design, given that reef size is relative to reef construction cost.

This general model can apply to any reef-resident zooplanktivorous fishes, i.e. those that use the reef structure for refuge and forage the surrounding pelagic environment, although the model depends on species-specific traits such as average body size and swim speed. The zooplankton biomass and current velocity input values were selected to reflect the harshest ecological conditions observed during the survey period (i.e. lowest density of available zooplankton and slowest observed daily current velocity) in order to conservatively estimate output values. To create the most general model possible, it was assumed that the internal reef volume was not part of the foraging volume (whereas fish could forage for zooplankton inside the reef in Model 1). This is true for many modern concrete artificial reefs, which, unlike the artificial reef in this study, are not necessarily designed to encourage water flow through the structure. Like Model 1, this model used a Monte Carlo simulation to include parameter variation in the model, and this is detailed in the following section. See Table 1 for parameter descriptions and values.

The maximum zooplanktivore density $\left(\operatorname{Den}_{L} ;\right.$ fish $\mathrm{m}^{-3}$ ) that a specific reef of length $L$ (length and width are assumed to be equal) is capable of supporting in its foraging volume $\left(V f_{L} ; \mathrm{m}^{3}\right)$ was calculated as:

$$
\operatorname{Den}_{L}=\frac{N_{L}}{V f_{L}}
$$

where $N_{L}$ is the abundance of zooplanktivores at the artificial reef of length $L$. $N_{L}$ was calculated by assuming that all zooplanktivores must be able to 
simultaneously seek refuge within the reef (volume $\left.V r_{L}\right)$, and that the within-reef fish density is equal to the maximum within-reef fish density observed at this study's artificial reef $\left(D e n_{\max }\right)$. Thus, all artificial reefs in Model 2 have an equal maximum within-reef density, independent of reef size.

$V r_{L}\left(\mathrm{~m}^{3}\right)$ is the within volume of a reef of length $L$ (m), calculated as:

$$
V r_{L}=L^{2} \times H
$$

where the simulated reef's length $(L)$ and width are considered equal, and $H$ is reef height $(\mathrm{m})$. Reef height was equal to $4 \mathrm{~m}$ in this model and held constant because artificial reef units are often fixed in height. The height used is arbitrary and can be customised for specific reefs, but the general shapes of the relationships from Model 2 are independent of reef height.

$V f_{L}$ is the foraging volume $\left(\mathrm{m}^{3}\right)$ surrounding an artificial reef of length $L$, calculated as:

$$
V f_{L}=V t_{L}-V r_{L}
$$

where $V t_{L}\left(\mathrm{~m}^{3}\right)$ is the total volume of a reef of length $L$, including its surrounding foraging volume, calculated as:

$$
V t_{L}=\left(L+D_{\max } \times 2\right)^{2} \times\left(H+D_{\max }\right)
$$

where $D_{\max }$ is the maximum distance $(\mathrm{m})$ that a zooplanktivore will forage from shelter under the risk of predation. By using a generic function for $D_{\max }$ (adapted from Biesinger et al. 2011), the model is applicable to a variety of reef-resident fishes and differing predator-prey relationships. $D_{\max }$ was calculated as:

$$
D_{\max }=\frac{D_{\mathrm{v}}}{\frac{S_{\text {pred }}}{S_{\text {prey }}}}+1
$$

where $D_{\mathrm{v}}$ is the mean viewing distance $(\mathrm{m}), S_{\text {pred }}$ $\left(\mathrm{m} \mathrm{s}^{-1}\right)$ is the swimming speed of a characteristic predator of zooplanktivorous fishes (for this model, the yellowtail kingfish Seriola lalandi), and $S_{\text {prey }}(\mathrm{m}$ $\mathrm{s}^{-1}$ ) is the swim speed of a zooplanktivore (for this model, A. strigatus). $S_{\text {pred }}$ and $S_{\text {prey }}$ were estimated using a derived relationship between swim speed, fish length and caudal fin aspect ratio (Sambilay 1990):

$$
\begin{aligned}
\log _{10}(S a) & =-0.828+0.6196 \log _{10}(L) \\
& +0.3478 \log _{10}(A R)+0.7621(M o)
\end{aligned}
$$

where $S a$ is the absolute swim speed $\left(\mathrm{km} \mathrm{h}^{-1}\right.$; converted to $\mathrm{m} \mathrm{s}^{-1}$ for use in Eq. 12), $L$ is the standard length of the fish (cm), Mo is swimming mode (0 for sustained and 1 for burst speeds), and $A R$ is the aspect ratio of the caudal fin, calculated using Eq. 2 for A. strigatus $(\mathrm{n}=53)$ and S. lalandi $(\mathrm{n}=8)$. Burst speed (i.e. $M o=1$ ) was used as the swimming mode for both $S_{\text {pred }}$ and $S_{\text {prey }}$ based on the assumption that both species will maximise their swimming speeds during a predation event. The $S_{\text {pred }}$ value estimated for yellowtail kingfish using Eq. 13 agreed closely with empirical swim speed data for this species (S. Brodie unpubl. data).

Food availability was determined by dividing the total amount of zooplankton supplied to a reef's foraging volume by the zooplankton required to sustain fish consumption (calculated using Eq. 1). A value $<1$ for this ratio shows that there is not enough zooplankton to support a population's consumption. A value much larger than 1 suggests that there is more zooplankton available than can be consumed and food is unlikely to be a limiting factor. This ratio $\left(C_{\text {ratio }}\right)$ is calculated as:

$$
C_{\text {ratio }}=\frac{B_{L}}{C_{\mathrm{t}}}
$$

where $C_{\mathrm{t}}$ is the total consumption of zooplankton by an individual zooplanktivore $\left(\mathrm{mg} \mathrm{fish} \mathrm{f}^{-1} \mathrm{~d}^{-1}\right)$, and $B_{L}$ is the supply of zooplankton biomass to each zooplanktivore within the foraging volume of a reef of length $L\left(\mathrm{mg}\right.$ fish $\left.^{-1} \mathrm{~d}^{-1}\right)$, calculated as

$$
B_{L}=B_{\mathrm{a}} \times \operatorname{Vin}_{L} \times R_{L}
$$

where $\operatorname{Vin}_{L}\left(\mathrm{~m}^{-3} \mathrm{fish}^{-1}\right)$ is the foraging volume available to an individual zooplanktivore, $R_{L}$ (periods $\mathrm{d}^{-1}$ ) is the rate that the foraging volume is replaced by prevailing coastal currents, and $B_{\mathrm{a}}$ is the available biomass of zooplankton allocated to an individual zooplanktivore for consumption (mg fish ${ }^{-1} \mathrm{~m}^{-3}$ ), calculated as:

$$
B_{\mathrm{a}}=B_{\mathrm{f}} \times P_{\text {con }}
$$

where $P_{\text {con }}$ is the proportion of the total zooplankton supply allocated to the zooplanktivore for consumption, which is necessary to account for the requirements of other zooplanktivorous organisms on the reef (e.g. barnacles, ascidians, other fishes) and was given a mean value of 0.25 in this model based on relative biomass estimates (Scott et al. 2015, J. Smith unpubl. data). $B_{\mathrm{f}}\left(\mathrm{mg} \mathrm{m}^{-3}\right)$ is the biomass of zooplankton capable of being foraged for by a zooplanktivore. $B_{\mathrm{f}}$ was calculated as the amount of the minimum environmentally available biomass of zooplankton before predation observed at the artificial reef $\left(B b_{\min }\right)$ that is available to A. strigatus, based on the observed prey size-selection. 
$\operatorname{Vin}_{L}$ was calculated as:

$$
\operatorname{Vin}_{L}=\frac{V f_{L}}{N_{L}}
$$

where $V f_{L}\left(\mathrm{~m}^{3}\right)$ is the total foraging volume surrounding an artificial reef with a length $L$ (Eq. 10), and $N_{L}$ is the abundance of zooplanktivores within the same reef. $R_{L}$ (periods $\mathrm{d}^{-1}$ ) was calculated as:

$$
R_{L}=\frac{24 \times 60 \times 60}{P e r}
$$

where Per is from Eq. 7, but replaces mean observed current velocity ( $\mathrm{Vel}$ ) with the minimum observed current velocity at this artificial reef ( $\left.V e l_{\text {mino }}\right)$ to conservatively estimate $R_{L}$.

$C_{\mathrm{t}}$ was calculated as:

$$
C_{\mathrm{t}}=\frac{\frac{Q}{B} \times W \times P_{\mathrm{zoo}}}{365}
$$

where $Q / B\left(\mathrm{yr}^{-1}\right)$ is the consumption rate of a zooplanktivore as a function of biomass (Eq. 1), $W$ (mg) is the mean weight of an individual zooplanktivore, and $P_{\text {zoo }}$ is the observed mean proportion of a zooplanktivores diet made up by zooplankton.

\section{Monte Carlo simulation and sensitivity analysis}

Both Model 1 and Model 2 contained parameters with uncertain or variable values, so a Monte Carlo simulation was used to incorporate this parameter variation into model outputs. Each model was iterated 5000 times, and the mean and variance calculated from these iterations. Each parameter's sampling distribution was either a normal, lognormal, or beta distribution (Table 1). The lognormal was used when there was evidence the data were skewed, and the beta distribution was used for proportion data. Standard deviations were generated from raw data wherever possible, and standard errors were used when the goal was to generate error in estimating the population mean, rather than variation at the individual level.

A sensitivity analysis was done to quantify the relative importance of parameter variables in both Model 1 and Model 2. A subset of parameters was selected from each model (Table 1), avoiding nested or obviously collinear parameters. The Monte Carlo simulation for each model was then used to randomly sample each parameter by its mean, or its mean $\pm 10 \%$. This was done 5000 times, and the linear model was fitted to the resulting dataset (Smith et al. 2012) using parameters standardised according to Kleijnen (1997). The response variable in Model 1 was the depletion (\%) of total zooplankton biomass, and the response variable for Model 2 was the reef length $(\mathrm{m})$ at which the food supplied:food required ratio $=1$.

\section{RESULTS}

\section{Diet of Atypichthys strigatus}

A. strigatus fed predominantly on zooplankton ( $93 \%$ of the diet; Table 2 ), and crustaceans dominated the identifiable biomass of observed stomach contents (Fig. S1 in the Supplement). The proportion of copepod biomass within the diet of A. strigatus was found to exceed all other identifiable prey groups combined (Table 2). Non-zooplanktonic prey items were infrequent components of the diet $(<17 \%$ occurrence). Much of the diet was too digested for identification, but diet studies of mado in similar environments support the dominance of zooplankton in their diet (Glasby \& Kingsford 1994, H. T. Schilling, J. A. Smith, J. D. Everett, D. P. Harrison, I. M. Suthers unpubl.). The parameter $P_{\text {zoo }}$ was varied to account for this uncertainty (Table 1) and took values between 60 and $100 \%$ during simulations. The total mean wet biomass of $A$. strigatus stomach contents was $466.4 \mathrm{mg}( \pm 39.3 \mathrm{SE})$, or $0.013 \mathrm{mg}$ food per $\mathrm{mg} A$. strigatus $( \pm 0.001 \mathrm{SE})$.

Table 2. Mean proportion $( \pm \mathrm{SE})$ by wet mass of prey items in the diet of Atypichthys strigatus $(\mathrm{n}=55)$

\begin{tabular}{|lcc|}
\hline Prey category & $\begin{array}{c}\text { Proportion of } \\
\text { A. strigatus diet }\end{array}$ & $\begin{array}{c}\text { Occurrence } \\
(\%)\end{array}$ \\
\hline Copepod & $0.160(0.012)$ & 100 \\
Shrimp & $0.032(0.006)$ & 65.5 \\
Ostracod & $0.010(0.002)$ & 52.7 \\
Amphipod & $0.002(0.001)$ & 10.9 \\
Zoea & $0.014(0.004)$ & 41.8 \\
Nauplius & $0.001(0.001)$ & 5.5 \\
Gastropod & $0.009(0.005)$ & 10.9 \\
Mollusc & $0.013(0.009)$ & 5.5 \\
Plant material & $0.010(0.004)$ & 16.4 \\
Unidentifiable Crustacea & $0.167(0.011)$ & 100 \\
Unidentifiable & $0.583(0.017)$ & 100 \\
Total zooplankton & $0.929^{\mathrm{a}}(0.022)$ & - \\
aExcludes unidentifiable material & \\
\hline
\end{tabular}




\section{Foraging volume and density of $\boldsymbol{A}$. strigatus}

The observed density of $A$. strigatus declined as distance from the reef increased (Fig. 4) and A. strigatus were not observed farther than $4 \mathrm{~m}$ from the study reef. The density observed within the reef (3.81 A. strigatus $\mathrm{m}^{-3} \pm 0.67 \mathrm{SE}$ ) greatly exceeded the mean density of all foraging bins surrounding the reef $\left(0.73 \mathrm{~A}\right.$. strigatus $\left.\mathrm{m}^{-3}\right)$. The foraging volume available to $A$. strigatus increased non-linearly with increasing distance from the reef (Fig. S2 in the Supplement). Reef volume was calculated as $663.6 \mathrm{~m}^{3}$ and the total foraging volume (within reef plus surrounding volume to $4 \mathrm{~m}$ from reef) was $2879 \mathrm{~m}^{3}$.

\section{Consumption by $A$. strigatus}

A. strigatus at the artificial reef were estimated to consume on average 8.88 times their biomass annually $(Q / B)$, which equated to an average of $0.77 \mathrm{~g}$ (0.10 SD) A. strigatus ${ }^{-1} \mathrm{~d}^{-1}$. Caudal fin aspect ratio did not significantly correlate with fish size $(\mathrm{r}=0.21$, $\mathrm{p}=0.14, \mathrm{n}=53)$, and therefore the mean $A R$ of $A$. strigatus $(2.29 \pm 0.47 \mathrm{SD})$ was applied to the multiple regression model (Eq. 1). Mean individual body mass of A. strigatus was calculated as $33.9 \mathrm{~g}$ (1.6 SE; $\mathrm{n}=55)$.

\section{Zooplankton supply and availability}

A. strigatus exhibited prey size-selection, and the most commonly selected prey size was $601-800 \mu \mathrm{m}$, despite the smallest size classes of zooplankton $(<200$ and $200-400 \mu \mathrm{m})$ being the most environmentally abundant (Fig. S3A in the Supplement). The abundance of zooplankton prey items in size classes larger than 601-800 $\mu \mathrm{m}$ declined in approximate proportion to the environmental availability (Fig. S3A).

The observed mean total biomass of zooplankton up-current of the artificial reef was $871 \mathrm{mg} \mathrm{m}^{-3}$ $( \pm 168 \mathrm{SE} ;$ Fig. S3B). The observed size-selection of A. strigatus for zooplankton $<200,200-400$ and 401-600 $\mu \mathrm{m}$ was determined to equal zero, 0.02 and 0.46 , respectively, while selection for size classes $\geq 601-800 \mu \mathrm{m}$ were assumed all equal to 1 . Thus, the mean biomass of zooplankton available to A. strigatus at this artificial reef under the observed pattern of prey size-selection was $637 \mathrm{mg} \mathrm{m}^{-3}\left( \pm 109 \mathrm{SE}_{\text {; }}\right.$ Fig. S3B), which represented $73 \%$ of the total zooplankton biomass.

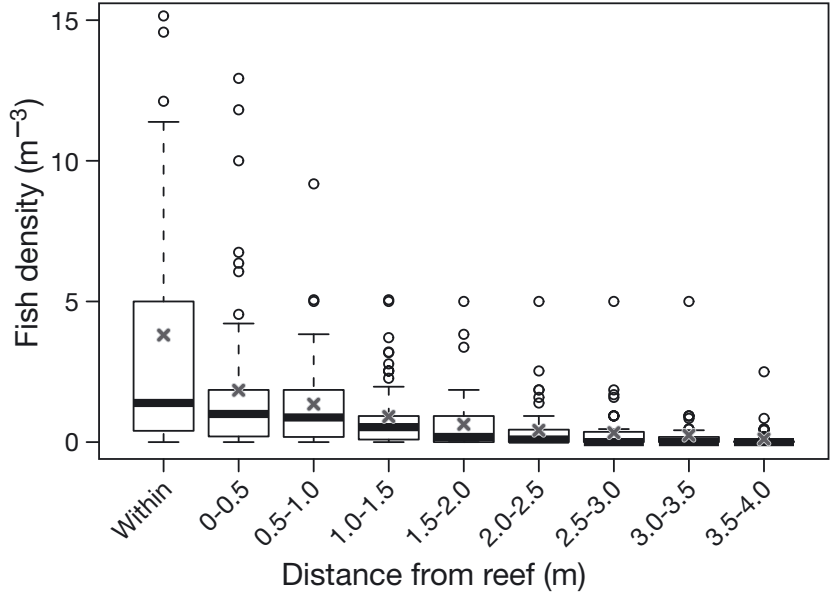

Fig. 4. Quantile boxplots of densities of Atypichthys strigatus (fish $\mathrm{m}^{-3}$ ) at the artificial reef within specific foraging distance bins. Each value represents a single observation from video footage ( $\mathrm{n} \approx 80$ for each binned foraging distance). Grey crosses denote mean values. Thick black line $=$ median; box = interquartile range $(\mathrm{IQR})$; whiskers = maximum of $1.5 \times \mathrm{IQR}_{\text {; }}$ circles $=$ outliers

Mean daily current velocity at the artificial reef from June to August 2013 and December to February $2013 / 2014$ was $0.091 \mathrm{~m} \mathrm{~s}^{-1}( \pm 0.04 \mathrm{SD})$. Maximum and minimum daily current velocities observed during this period were 0.178 and $0.042 \mathrm{~m} \mathrm{~s}^{-1}$, respectively.

\section{Model 1: Zooplankton depletion}

The A. strigatus population at this study's coastal artificial reef was estimated to consume $2906 \mathrm{~g}$ $( \pm 425 \mathrm{SD})$ of zooplankton per day, which is approximately $1.0 \mathrm{~g} \mathrm{~m}^{-3}$ of reef habitat (reef and foraging volumes combined) per day. This equates to an average depletion of $0.35 \%( \pm 0.13 \mathrm{SD})$ of the total zooplankton biomass delivered to the artificial reef (Fig. 5), or $0.49 \%( \pm 0.17 \mathrm{SD})$ depletion of the available zooplankton biomass. The size-specific analysis of zooplankton depletion revealed that size class 601-800 $\mu \mathrm{m}$ were most depleted by $A$. strigatus predation; equal to $0.94 \%$ (1521 g) of the total biomass of that size class (Fig. 5). Zooplankton within size classes 200-400 and $>1600 \mu \mathrm{m}$ were least depleted by $A$. strigatus predation (excluding size class $<200 \mu \mathrm{m}$, which was not consumed by A. strigatus), equal to $0.04 \%$ of the total binned biomass or $30 \mathrm{~g} \mathrm{~d}^{-1}$ and $0.02 \%$ of the total binned biomass or $20 \mathrm{~g} \mathrm{~d}^{-1}$, respectively. There was considerable variation in these depletion estimates (Fig. 5) due to the variation and uncertainty in the foraging volume, the supply of 


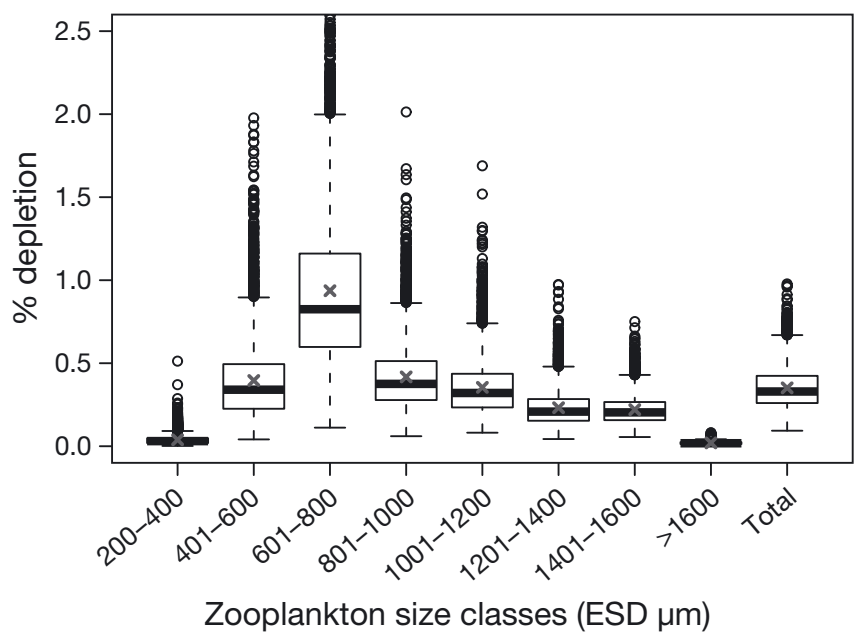

Fig. 5. Percentage of total zooplankton biomass depleted per size class by Atypichthys strigatus; grey crosses denote mean values. Box-plots as in Fig. 4. The spread of these quantile boxplots illustrates the variation in zooplankton depletion across the 5000 iterations in the Monte Carlo simulation of Model 1. ESD: equivalent spherical diameter

zooplankton, and mado density and consumption (Table 1). Sensitivity analysis showed that all these model facets are equally influential in the model (Fig. S4A in the Supplement). for square reefs $4 \mathrm{~m}$ in height, and increasing this height would decrease the reef length at which food limitation begins. Changing reef shape would also change these relationships. As in Model 1, there was considerable uncertainty around the estimates due to variation and uncertainty in model parameters (Table 2). The sensitivity analysis likewise showed that all parameters are equally influential for determining the reef size at food limitation (Fig. S4B).

\section{DISCUSSION}

This study revealed that a coastal artificial reef can support a large biomass of zooplanktivorous fish, demonstrating the value of zooplankton to fish biomass on such reefs. The small distance from the reef that these fish were willing to forage suggests that this zooplankton could not be exploited without the refuge this artificial reef provides. Approximately 3800 individual Atypichthys strigatus with a biomass of $\sim 130 \mathrm{~kg}$ populated the reef and immediate foraging volume. Although this species consumed predominantly zooplankton, its total consumption depleted less than $0.5 \%$ of the prevailing supply of zooplankton to this reef. Even though this coastal artificial reef received a substantial supply of zoo-

\section{Model 2: Reef size}

As the modelled reef became larger, foraging volume per unit reef volume decreased, which resulted in: (1) higher possible densities of reef-resident zooplanktivorous fish in the surrounding water, due to the increased refuge; and (2) a corresponding decline in zooplankton availability (Fig. 6). Given minimum observed values for current velocity $\left(V e l_{\text {mino }}\right)$ and zooplankton biomass $\left(B b_{\min }\right.$ Table 1$)$, the zooplankton supplied to reefs larger than $\sim 40 \mathrm{~m}$ in length (between 25 and $55 \mathrm{~m}$ ) would not support the required consumption rate of the maximum density of the resident zooplanktivore A. strigatus (Fig. 6). The biomass of zooplankton available for consumption on reefs $<40 \mathrm{~m}$ in length increased exponentially with decreasing reef size. The maximum density of the resident zooplanktivore in the foraging volume increased asymptotically with reef size (Fig. 6). These results are

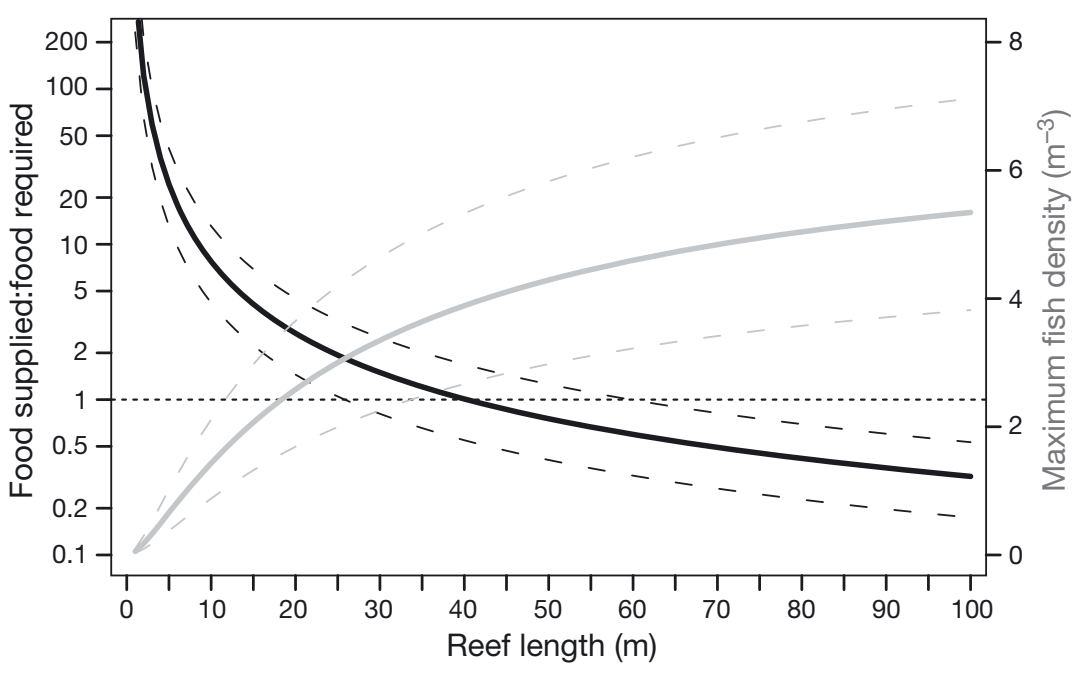

Fig. 6. Illustration of the influence of reef size on food (zooplankton) availability and maximum density of resident zooplanktivorous fish. Food availability is the ratio of food supplied to food required, which declines as reefs get larger. Black lines: mean (solid line) and 95\% CI (dashed lines); axis is $\log _{10}$-scaled; $C_{\text {ratioo }}$ Eq. (14). When this ratio falls below 1 (dotted line), there is not enough food to support the maximum density of fish. The maximum density of zooplanktivorous fish in a reef's foraging volume $\left(D e n_{L}\right.$ Eq. 8) increases with reef size. Grey lines: mean (solid line) and 95\% CI (dashed lines). This suggests that there is an intermediate range of reef sizes that offer large abundance of resident zooplanktivores while avoiding food limitation 
plankton, this study showed that increasing the size of artificial reefs negatively affects the ability of resident zooplanktivorous fish to achieve their required daily food ration, which will eventually limit fish density. Until this limitation occurs, however, increasing reef size allows for higher densities of zooplanktivorous fish within the surrounding foraging volume, and this abundance of prey fish may create benefits for recreational fishers. This illustrates the ecological cost of an increasing reef size - there is more refuge volume for reef residents but less foraging volume to support their consumption. These findings suggest that zooplankton can contribute greatly to resident fish production on coastal artificial reefs but that the dynamics of this trophic link is dependent on reef size, which is a factor that could be exploited when designing and deploying artificial reefs.

\section{Zooplankton consumption by reef fish}

The zooplanktivore A. strigatus population was estimated to consume a large amount of zooplankton at this artificial reef $\left(2.9 \mathrm{~kg} \mathrm{~d}^{-1} \pm 0.5 \mathrm{SD}\right)$, yet this was only a tiny proportion of the average total zooplankton biomass supplied to the reef $(0.35 \%)$. This indicates that the pelagic environment is a vast source of energy that can be incorporated into coastal reef systems via consumption by zooplanktivorous fishes, although the importance of this link to fish production is likely to be proportional to a reef's exposure to ocean currents (Hamner et al. 1988). The large proportion of zooplankton in the A. strigatus diet, and their high abundance and resident behaviour, suggest that the supply of food from the pelagic environment is a very important driver of this reef's function.

The input of pelagic energy into reef ecosystems via zooplanktivory may be common and integral to the function of coastal and offshore reefs (Hamner et al. 1988, Bortone 1998, Yahel et al. 2005). This study has only considered one abundant species of zooplanktivore, but large abundances of other reefassociated zooplanktivorous fishes such as yellowtail scad Trachurus novaezelandiae have also been recorded (NSW Department of Primary Industries 2013, Scott et al. 2015). Hence, the consumption values in this study only reflect a part of the total energy that is transferred from the pelagic environment to this reef area via fish zooplanktivory. What is more, planktivory by sessile invertebrates can also be very large (Glynn 1973, Reiswig 1974, Ayukai 1995), so our results may only represent a fraction of the coastal reef biomass supported by zooplankton. The com- bined consumption of zooplankton by reef-associated fishes and invertebrates forms a 'pelagic pathway' of energy to artificial and natural reefs alike (Kingsford \& MacDiarmid 1988, Cresson et al. 2014), and it is the synthesis of this energy and transfer to higher trophic levels that is one of the key processes that can underpin biomass production on artificial reefs (Lindberg 1997, Leitão 2013, Cresson et al. 2014).

\section{Influence of reef size on zooplanktivorous fish}

The foraging behavior of reef-resident planktivores such as A. strigatus can be generally described as foraging the volume surrounding a central reef or refuge, within a distance of the refuge that allows for retreat to avoid predation (Hamner et al. 1988, Motro et al. 2005, Biesinger et al. 2011). A maximum foraging distance $\left(D_{\max }\right)$ defines this foraging volume surrounding reef habitats. An interesting outcome of a fixed $D_{\text {max }}$ is a non-linear relationship between reef size and foraging volume. As a result, when reef size increases the foraging volume surrounding a reef declines relative to the reef refuge volume. This nonlinearity was found to have an important influence on the dynamics of reef-resident zooplanktivorous fish.

The availability of zooplankton to zooplanktivorous fish declined as reef size increased, according to the relationship between refuge volume and foraging volume. Although zooplanktivorous fish may not forage to the extent of $D_{\max }$ when their zooplankton food is abundantly available, this foraging limit becomes more important as reef size (and fish abundance) increases and the ratio of food supplied to food required becomes increasingly small. For the reef system modelled in this study, reefs greater than $\sim 40 \mathrm{~m}$ in length have insufficient foraging volume to feed the maximum density of resident zooplanktivorous fish, during the periods of lowest current flow (Fig. 6). In other words, large reefs have refuge for a high abundance of fish but lack the foraging volume in which to feed them. This means that the trophic relationship between zooplankton and reef-resident zooplanktivorous fishes becomes increasingly inefficient with increasing reef size, and the density of zooplanktivores should decline due to food limitation. Studies have observed higher fish densities on smaller reefs than on larger reefs (Bohnsack et al. 1994, Jordan et al. 2005), which provides support for this relationship.

An upside of increasing reef size is the increased provision of refuge volume, which can allow higher densities of reef-resident zooplanktivorous fish within 
the surrounding foraging volume. Again, this is due to the non-linear relationship between the refuge and foraging volumes and the assumption that maximum fish density in the refuge volume is largely independent of reef size. In the modelled scenarios in this study, maximum zooplanktivore density began to asymptote on reefs with a length or width of $\sim 50 \mathrm{~m}$ (Fig. 6), but the actual density would probably decline given density-dependent responses to the declining abundance of food.

The Monte Carlo simulations provided insight into the considerable variation and uncertainty in model parameters. The variation in zooplankton depletion, for example, depends on real variation in parameters such as current speed, zooplankton biomass, and water visibility but also on uncertainty in our estimates of parameters such as mean mado density and mean proportion of zooplankton in the diet. The sensitivity analysis revealed that all parameters are similarly influential, but targeting research towards a better understanding of species-specific foraging volumes could be a priority. This includes quantifying diurnal patterns in foraging and movement, especially as much planktivory may be diurnal (Yahel et al. 2005), as these patterns could further influence zooplankton availability. Future models may also benefit from incorporating density-dependence into calculations of fish abundance. In Model 2 , the abundance of zooplanktivorous fish on a given reef was determined by the refuge volume and a fixed fish density within that volume. The relationships between reef size and both food supply and fish density assume that this 'refuge fish density' remains constant, but it is likely this density will vary in response to density-dependent competition for food and/or refuge. This study focused on a single species using data from a single reef, and much can be gained by exploring foraging patterns across multiple reefs and for multiple species, including accounting for interactions between species (Klages et al. 2014).

\section{Management implications}

This study has shown that the size of artificial reefs can have a great influence on resident zooplanktivorous fish, such that large reefs can be food limited and small reefs can be considered refuge limited. Both refuge volume and foraging volume are drivers of fish abundance, but the non-linear relationship between them means that small reefs can have an abundance of food but little refuge, while large reefs can have lots of refuge but insufficient foraging volume to support all possible residents. This suggests that an optimum reef size exists that can successfully trade-off between food and refuge. Understanding the limitations of artificial reefs that are either too small or overly large is essential for designing reefs that effectively facilitate the important trophic link between zooplankton and reef-resident fishes. These limitations are particularly important, as the size of an artificial reef can represent its construction cost, and the size of individual units can vary greatly (Bohnsack et al. 1994, Cresson et al. 2014, Scott et al. 2015). Large reefs cost more but do not necessarily optimise the trophic transfer of energy from zooplankton to reef-resident zooplanktivorous fishes. A common alternative to the deployment of one large reef is to create multiple smaller reefs that combined have the same reef volume but have independent foraging volumes that do not overlap (Bortone et al. 1998, Brandt \& Jackson 2013). This strategy would be beneficial as it is likely to result in a similar abundance of individual reef-resident zooplanktivorous fishes but a larger per-capita food supply.

The orientation of artificial reefs to prevailing currents, and the effect of this on the trophic transfer of energy from the pelagic environment to the reef assemblage, is an aspect of reef design and deployment that has been discussed only rarely (Pickering \& Whitmarsh 1997). It has been suggested the long axis of an artificial reef could be orientated perpendicular to the prevailing current (Mathews 1981, Pickering \& Whitmarsh 1997) to maximise the supply of zooplankton to all zooplanktivorous reef animals. The findings in this study highlight the real value of this idea for optimising the production of zooplanktivores on coastal reefs. Artificial reefs could realistically be very long, and support a high abundance of reef-resident zooplanktivores, provided that this long axis is perpendicular to a dominant current direction. The effect of reef shape and size on the local hydrology and subsequent delivery of zooplankton also deserves investigation.

The benefit of optimising the production of zooplanktivorous fish will depend on an artificial reef's management objectives, which include providing fishing opportunities, habitat offsets, and coastal protection (Baine 2001). For reefs deployed to provide fisheries benefits, increasing the presence and production of targeted species is a key objective, and optimising the production of zooplanktivores may promote this by increasing the presence of piscivorous fish. Zooplanktivores not only provide significant organic matter for benthic reef assemblages 
(Bray et al. 1981, 1986), but they are also preyed upon by piscivorous species (Bulman et al. 2001, Young et al. 2010) commonly targeted by anglers. One of the most common species observed on the reef in this study is the prized piscivore yellowtail kingfish Seriola lalandi (Scott et al. 2015). The transfer of energy from zooplankton to local fish production on artificial reefs across multiple trophic levels remains to be quantified (Grossman et al. 1997), but it is likely that zooplanktivory by resident fish is a dominant process contributing to a larger food web.

In conclusion, this study showed that the trophic link between zooplankton and zooplanktivorous fishes is an important avenue of energy for reef assemblages, and one that probably contributes much to fish production on coastal artificial reefs. This study also revealed the trade-off between food supply and habitat supply as reef size changes and that food limitation is probably a key process driving resident zooplanktivore production on larger reefs. Ways to facilitate the consumption of zooplankton by zooplanktivorous fishes should be considered when planning future reefs, including the manipulation of reef size and shape, as this trophic link may have the greatest potential for enhancing the production of fish biomass from artificial reefs.

Acknowledgements. We thank Derrick Cruz and Hayden Schilling for their assistance with fieldwork. This research was funded by an Australian Research Council Linkage Project (LP120100592). This study was done under University of NSW Animal Care and Ethics Committee (ACEC) approval \#10/15B.

\section{LITERATURE CITED}

Ayukai T (1995) Retention of phytoplankton and planktonic microbes on coral reefs within the Great Barrier Reef, Australia. Coral Reefs 14:141-147

Baine M (2001) Artificial reefs: a review of their design, application, management and performance. Ocean Coast Manag 44:241-259

$>$ Berg J (1979) Discussion of methods of investigating the food of fishes, with reference to a preliminary study of the prey of Gobiusculus flavescens (Gobiidae). Mar Biol 50:263-273

- Biesinger Z, Bolker BM, Lindberg WJ (2011) Predicting local population distributions around a central shelter based on a predation risk-growth trade-off. Ecol Model 222: 1448-1455

Biesinger Z, Bolker BM, Marcinek D, Lindberg WJ (2013) Gag (Mycteroperca microlepis) space-use correlations with landscape structure and environmental conditions. J Exp Mar Biol Ecol 443:1-11

Bohnsack JA (1989) Are high densities of fishes at artificial reefs the result of habitat limitation or behavioral preference? Bull Mar Sci 44:631-645
Bohnsack JA, Harper DE, McClellan DB, Hulsbeck M (1994) Effects of reef size on colonization and assemblage structure of fishes at artificial reefs off southeastern Florida, USA Bull Mar Sci 55:796-823

Bombace G, Fabi G, Fiorentini L, Speranza S (1994) Analysis of the efficacy of artificial reefs located in five different areas of the Adriatic sea. Bull Mar Sci 55:559-580

Bortone SA (1998) Resolving the attraction-production dilemma in artificial reef research: some yeas and nays. Fisheries (Bethesda, MD) 23:6-10

Bortone SA, Cody RP, Turpin RK, Bundrick CM (1998) The impact of artificial reef fish assemblages on their potential forage area. Ital J Zool 65:265-267

Brandt JR, Jackson DC (2013) Influences of artificial reefs on juvenile red snapper along the Mississippi Gulf coast. Mar Coast Fish 5:1-10

> Bray RN, Miller AC, Geesey GG (1981) The fish connection: a trophic link between planktonic and rocky reef communities? Science 214:204-205

> Bray RN, Purcell LJ, Miller AC (1986) Ammonium excretion in a temperate-reef community by a planktivorous fish, Chromis punctipinnis (Pomacentridae), and potential uptake by young giant kelp, Macrocystis pyrifera (Laminariales). Mar Biol 90:327-334

Brickhill MJ, Lee SY, Connolly RM (2005) Fishes associated with artificial reefs: attributing changes to attraction or production using novel approaches. J Fish Biol 67:53-71

Bulman C, Althaus F, He X, Bax NJ, Williams A (2001) Diets and trophic guilds of demersal fishes of the south-eastern Australian shelf. Mar Freshw Res 52:537-548

Charbonnel E, Serre E, Ruitton S, Harmelin JG, Jensen AC (2002) Effects of increased habitat complexity on fish assemblages associated with large artificial reef units (French Mediterranean coast). ICES J Mar Sci 59:S208-S213

> Claudet J, Pelletier D (2004) Marine protected areas and artificial reefs: a review of the interactions between management and scientific studies. Aquat Living Resour 17: 129-138

Cresson P, Ruitton S, Harmelin-Vivien M (2014) Artificial reefs do increase secondary biomass production: mechanisms evidenced by stable isotopes. Mar Ecol Prog Ser 509:15-26

Ebeling AW, Larson RJ, Alevizon WS, Bray RN (1980) Annual variability of reef-fish assemblages in kelp forests off Santa Barbara, California. Fish Bull US 78:361-377

Edgar GJ, Stuart-Smith RD (2014) Systematic global assessment of reef fish communities by the Reef Life Survey program. Scientific Data 1, 140007

Fowler AM, Booth DJ (2013) Seasonal dynamics of fish assemblages on breakwaters and natural rocky reefs in a temperate estuary: consistent assemblage differences driven by sub-adults. PLoS ONE 8:e75790

Frazer TK, Lindberg WJ (1994) Refuge spacing similarly affects reef-associated species from three phyla. Bull Mar Sci 55:388-400

> Glasby TM, Kingsford MJ (1994) Atypichthys strigatus (Pisces: Scorpididae): an opportunistic planktivore that responds to benthic disturbances and cleans other fishes. Aust J Ecol 19:385-394

> Glenn CL, Ward EJ (1968) 'Wet weight' as a method of measuring stomach contents of Walleyes, Stizostedion vitreum vitreum. J Fish Res Board Can 25:1505-1507

Glynn PW (1973) Ecology of a Caribbean coral reef. The Pontes reef-flat biotope. Part 2. Plankton community with evidence tor depletion. Mar Biol 22:1-21 
Grossman GD, Jones GP, Seaman WJ Jr (1997) Do artificial reefs increase regional fish production? A review of existing data. Fisheries (Bethesda, MD) 22:17-23

Hamner WM, Jones MS, Carleton JH, Hauri IR, Williams DM (1988) Zooplankton, planktivorous fish, and water currents on a windward reef face: Great Barrier Reef, Australia. Bull Mar Sci 42:459-479

- Herman AW, Beanlands B, Phillips EF (2004) The next generation of optical plankton counter: the Laser-OPC. J Plankton Res 26:1135-1145

Hobson ES, Chess JR (1976) Trophic interactions among fishes and zooplankters near shore at Santa Catalina Island, California. Fish Bull US 74:567-598

Hobson ES, Chess JR (1978) Trophic relationships among fishes and plankton in the lagoon at Enewetak Atoll, Marshall Islands. Fish Bull US 76:133-153

> Hughes JM, Stewart J, Lyle JM, Suthers IM (2014) Topdown pressure on small pelagic fish by eastern Australian salmon Arripis trutta; estimation of daily ration and annual prey consumption using multiple techniques. J Exp Mar Biol Ecol 459:190-198

> Hyslop E (1980) Stomach contents analysis - a review of methods and their application. J Fish Biol 17:411-429

Jordan LKB, Gilliam DS, Spieler RE (2005) Reef fish assemblage structure affected by small-scale spacing and size variations of artificial patch reefs. J Exp Mar Biol Ecol 326:170-186

- Kingsford MJ, MacDiarmid AB (1988) Interrelations between planktivorous reef fish and zooplankton in temperate waters. Mar Ecol Prog Ser 48:103-117

Klages J, Broad A, Kelaher BP, Davis AR (2014) The influence of gummy sharks, Mustelus antarcticus, on observed fish assemblage structure. Environ Biol Fishes 97: 215-222

Kleijnen JPC (1997) Sensitivity analysis and related analyses: a review of some statistical techniques. J Stat Comput Simul 57:111-142

Leitão F (2013) Artificial reefs: from ecological processes to fishing enhancement tools. Braz J Oceanogr 61:77-81

> Li KT, Wetterer JK, Hairston NG Jr (1985) Fish size, visual resolution, and prey selectivity. Ecology 66:1729-1735

Lindberg WJ (1997) Can science solve the attractionproduction issue? Fisheries (Bethesda, MD) 22:10-13

Man H, Hodgkiss I (1977) Studies on the ichthyo-fauna in Plover Cove Reservoir, Hong Kong: feeding and food relations. J Fish Biol 11:1-13

Mathews H (1981) Artificial reefs site: selection and evaluation. In: Aska DY (ed) Artificial reefs: conference proceedings. Flor Sea Grant Rep 41:50-54

Miller MW (2002) Using ecological processes to advance artificial reef goals. ICES J Mar Sci 59:S27-S31

Motro R, Ayalon I, Genin A (2005) Near-bottom depletion of zooplankton over coral reefs: III: vertical gradient of predation pressure. Coral Reefs 24:95-98

NSW Department of Primary Industries (2013) Sydney offshore artificial reef. Annual environmental monitoring report 2012-13. New South Wales Government, Sydney

O'Brien WJ (1979) The predator-prey interaction of plank- tivorous fish and zooplankton. Am Sci 67:572-581

Palomares ML, Pauly D (1989) A multiple regression model for predicting the food consumption of marine fish populations. Aust J Mar Freshw Res 40:259-273

> Palomares ML, Pauly D (1998) Predicting food consumption of fish populations as functions of mortality, food type, morphometrics, temperature and salinity. Aust J Mar Freshw Res 49:447-453

Peterson CH, Grabowski JH, Powers SP (2003) Estimated enhancement of fish production resulting from restoring oyster reef habitat: quantitative valuation. Mar Ecol Prog Ser 264:249-264

> Pickering H, Whitmarsh D (1997) Artificial reefs and fisheries exploitation: a review of the 'attraction versus production debate', the influence of design and its significance for policy. Fish Res 31:39-59

> Powers SP, Grabowski JH, Peterson CH, Lindberg WJ (2003) Estimating enhancement of fish production by offshore artificial reefs: uncertainty exhibited by divergent scenarios. Mar Ecol Prog Ser 264:265-277

R Core Team (2015) R: a language and environment for statistical computing. R Foundation for Statistical Computing, Vienna. www.R-project.org/

Reiswig HM (1974) Water transport, respiration and energetics of three tropical marine sponges. J Exp Mar Biol Ecol 14:231-249

Sambilay VC (1990) Interrelationships between swimming speed, caudal fin aspect ratio and body length of fishes. Fishbyte 8:16-20

Scott ME, Smith JA, Lowry MB, Taylor MD, Suthers IM (2015) The influence of an offshore artificial reef on the abundance of fish in the surrounding pelagic environment. Mar Freshw Res 66:429-437

Seaman W (2007) Artificial habitats and the restoration of degraded marine ecosystems and fisheries. Hydrobiologia 580:143-155

Seaman W Jr, Buckley RM, Polovina JJ (1989) Advances in knowledge and priorities for research, technology and management related to artificial aquatic habitat. Bull Mar Sci 44:527-532

> Smith JA, Baumgartner LJ, Suthers IM, Ives MC, Taylor MD (2012) Estimating the stocking potential of fish in impoundments by modelling supply and steady-state demand. Freshw Biol 57:1482-1499

Suthers IM, Kelly D, Taggart CT, Middleton JH, Rissik D (2004) Entrainment and advection in an island's tidal wake, as revealed by light attenuance, zooplankton, and ichthyoplankton. Limnol Oceanogr 49:283-296

Wankowski JWJ (1979) Morphological limitations, prey size selectivity, and growth response of juvenile Atlantic salmon, Salmo salar. J Fish Biol 14:89-100

Yahel R, Yahel G, Genin A (2005) Near-bottom depletion of zooplankton over coral reefs: I: diurnal dynamics and size distribution. Coral Reefs 24:75-85

> Young JW, Lansdell MJ, Campbell RA, Cooper SP, Juanes F, Guest MA (2010) Feeding ecology and niche segregation in oceanic top predators off eastern Australia. Mar Biol 157:2347-2368

Submitted: August 20, 2015; Accepted: October 23, 2015 Proofs received from author(s): November 24, 2015
Editorial responsibility: Edward Durbin,

Narragansett, Rhode Island, USA 